\title{
Human monoclonal anti-TLR4 antibody negatively regulates lipopolysaccharide-induced inflammatory responses in mouse macrophages
}

\author{
YIWEN WANG $^{1}$, DANDAN GONG $^{2}$, CHUANXIA YAO $^{3}$, FENG ZHENG $^{1}$, \\ TINGTING ZHOU ${ }^{1}$, QINGXIN CAO ${ }^{1}$, XUHUI ZHU ${ }^{1}$, MAORONG WANG ${ }^{4}$ and JIN ZHU ${ }^{1,5}$ \\ ${ }^{1}$ Department of Epidemiology and Microbiology, Huadong Medical Institute of Biotechniques, Nanjing, Jiangsu 210002; \\ ${ }^{2}$ Department of Obstetrics and Gynecology, Nanjing Maternity and Child Health Care Hospital, \\ Obstetrics and Gynecology Hospital Affiliated to Nanjing Medical University, Nanjing, Jiangsu 210004; \\ ${ }^{3}$ Department of Infectious Disease, Anhui Medical University Affiliated with Bayi Clinical College, Hefei, Anhui 230000; \\ ${ }^{4}$ Institute of Liver Disease, Nanjing Jingdu Hospital, Nanjing, Jiangsu 210002; ${ }^{5}$ Department of Pathology, \\ Key Laboratory of Antibody Technique of The Ministry of Health, Nanjing Medical University, \\ Nanjing, Jiangsu 210029, P.R. China
}

Received August 2, 2019; Accepted March 26, 2020

DOI: $10.3892 / \mathrm{mmr} .2020 .11500$

\begin{abstract}
Previous studies have revealed that activation of the Toll-like receptor 4 (TLR4)-mediated proinflammatory signaling pathway plays an important role in acute inflammation, sepsis and chronic inflammatory disorders. Moreover, TLR4 significantly contributes to lipopolysaccharide (LPS)-induced immune response. Thus, modulation of the TLR4 pathway is an important strategy to specifically target these pathologies. The aim of the present study was to develop a complete human anti-TLR4 IgG2 antibody by screening human TLR4 Fab from a phage-display library and integrating it with constant regions of the heavy chain of human IgG2 via antibody engineering. ELISA, a BLItz system and fluorescence-activated cell sorting were used to assess its affinity. Furthermore, mouse-derived peritoneal macrophages were treated with human anti-TLR4 IgG2 and induced with LPS in vitro. Reverse transcription-quantitative PCR and western blotting were used to determine mRNA expression levels of cytokines and phosphorylation levels of signaling pathways, respectively. It was found that human anti-TLR4 $\operatorname{IgG} 2$ bound to TLR4 with a high affinity of $8.713 \times 10^{-10} \mathrm{M}$, and that preincubation with anti-TLR4 IgG2 inhibited the LPS-induced production of tumor necrosis factor- $\alpha$, interferon- $\beta$ and
\end{abstract}

Correspondence to: Professor Jin Zhu, Department of Epidemiology and Microbiology, Huadong Medical Institute of Biotechniques, 293 East Zhongshan Road, Nanjing, Jiangsu 210002, P.R. China

E-mail: zhujin1968@njmu.edu.cn

Key words: sepsis, human anti-Toll-like receptor 4 IgG2 antibody, lipopolysaccharide, macrophages interleukin- 6 mRNA expression levels in mouse peritoneal macrophages. It was also demonstrated that human anti-TLR4 IgG2 inhibited LPS-induced TLR4 signaling by reducing the phosphorylation of the $\mathrm{NF}-\kappa \mathrm{B}$, mitogen-activated protein kinase and interferon regulatory factor 3 signaling pathways. In addition, human anti-TLR4 $\mathrm{IgG} 2$ protected mice from LPS challenge with a survival rate of $40 \%$ and also significantly increased the survival time in the cecal ligation and puncture model. Therefore, it was speculated that human anti-TLR4 IgG2 plays a protective role against sepsis-associated injury and is potentially applicable for the treatment of infection-associated immune dysfunction.

\section{Introduction}

Toll-like receptors (TLRs), which have the most extensive spectrum of pathogen recognition, detect invading pathogens by recognizing pathogen-associated molecular patterns (PAMPs) and damage-associated molecular pattern molecules (DAMPs) $(1,2)$. TLR4, a TLR family member, plays an important role in innate immunity against allergy (3), obesity-associated metabolic disorders (4), apoptosis (5), infectious diseases (6), and inflammatory bowel diseases (7). Moreover, TLR4 is widely expressed on the surface of immune cells, including macrophages, neutrophils and lymphocytes (8).

Lipopolysaccharide (LPS), an endotoxin on the cell wall of Gram-negative bacteria, is a major PAMP (1). On recognizing LPS, TLR4 interacts with LPS via its cytosolic toll-interleukin (IL)-1 receptor (TIR) domain (9). Furthermore, LPS binds to LPS-binding protein (LBP) and CD14, which then transfers LPS to the TLR4/myeloid differentiation protein-2 (MD2) complex, which dimerizes and translocates to endosomes, triggering myeloid differentiation primary response gene 88 (MyD88)-dependent and MyD88-independent pathways (10). Moreover, the two pathways can induce phosphorylation of 
transcription factors, including nuclear factor $\kappa \mathrm{B}(\mathrm{NF}-\kappa \mathrm{B})$, activator protein 1 and interferon (IFN) regulatory factor 3 (IRF-3), to eventually promote the production of proinflammatory cytokines, such as tumor necrosis factor (TNF)- $\alpha$, IL-1, IL-6, IL-8, IFN- $\beta$ and IFN- $\gamma$ (11-13). The inflammatory response to LPS plays a key role in the defense against bacterial infections; however, excessive host reaction to LPS causes severe inflammatory conditions such as sepsis and fatal septic shock $(14,15)$. Therefore, regulation of TLR4-mediated signaling is critical for maintaining the intensity of the immune response and treating severe sepsis.

Monoclonal antibodies (mAbs) are a widely used pharmacotherapeutic approach in the treatment of various inflammatory diseases (16). Thus, the aims of the present study were to prepare a novel human monoclonal anti-TLR4 immunoglobulin G2 antibody by screening an anti-TLR4 Fab fragment from a human Fab phage-display library, and to examine whether human anti-TLR4 IgG2 decreases LPS-induced immune responses. The present results suggest that the entire human anti-TLR4 IgG2 antibody showed high affinity for TLR4 and functioned well against LPS-induced inflammatory processes in mouse macrophages.

\section{Materials and methods}

Reagents and mice. LPS used to stimulate inflammation responses was obtained from Sigma-Aldrich (Merck KGaA). RPMI-1640 medium, DMEM/F12 and FBS used for cell culture were purchased from Gibco (Thermo Fisher Scientific, Inc.). Diagnostic ELISA kits for the measurement of mouse TNF- $\alpha$ (cat. no. MTA00B), IL-6 (cat. no. M6000B) and IFN- $\beta$ (cat. no. MIFNB0) were obtained from R\&D Systems, Inc. C57BL/6J female mice (age, 6-8 weeks; weight, 20-25 g) were purchased from SLAC Laboratory Animal Company. The following specific antibodies were obtained from Cell Signaling Technology, Inc.: Anti-phosphorylated (p)-p38 (cat. no. 9215), anti-p38 (cat. no. 8690), anti-p-p65 (cat. no. 3033), anti-p65 (cat. no. 8242), anti-p-JNK (cat. no. 4668), anti-JNK (cat. no. 9258), anti-p-ERK (cat. no. 4376), anti-ERK (cat. no. 4695), anti-p-inhibitor of $\kappa \mathrm{B}(\mathrm{I} \kappa \mathrm{B})$ (cat. no. 2859), anti-IкB (cat. no. 4812), anti-p-IRF-3 (cat. no. 29047), anti-IRF-3 (cat. no. 11904), anti-p-IкB kinase (IKK) (cat. no. 2697), anti-IKK (cat. no. 8943) and anti- $\beta$-actin (cat. no. 8457). All the animal experiments were performed according to protocols that were approved by the Ethics Committee of Huadong Medical Institute of Biotechniques.

Cells and cell culture. Mouse peritoneal macrophages (MPM) were isolated by peritoneal lavage 3-4 days after intraperitoneal injection of mice with $2 \mathrm{ml}$ sterile $5 \%$ thioglycolate broth, as previously described (17). MPM were cultured in RPMI-1640 medium supplemented with $10 \%$ FBS and $1 \%$ antibiotic-antimycotic (Gibco; Thermo Fisher Scientific, Inc.) at $37^{\circ} \mathrm{C}$ with $5 \% \mathrm{CO}_{2}$.

Preparation of human anti-TLR4 IgG2. A phage-displayed library with $>10^{13}$ phage clones was used to screen the human Fab against TLR4, as previously described (18). A total of seven rounds of screening with precoated recombinant TLR4 protein were performed to ensure the specificity of the binding phage. VBASE2 database (vbase2.org/vbhelp.php) was used for analyzing the sequence of Fab. Cloned anti-TLR4 Fab was selected to develop complete human IgG2 via gene synthesis. The heavy $(\mathrm{H})$ and light $(\mathrm{L})$ chains were cloned separately into the pMH3 vector (AmProtein-China, Inc.). Recombinant IgG2 expression vectors (pMH3-anti-TLR4-IgG2-H and pMH3-anti-TLR4-IgG2-L) were expressed in Chinese hamster ovary (CHO) cells (American Type Culture Collection) which were cultured in DMEM/F12 supplemented with 10\% FBS (Gibco; Thermo Fisher Scientific, Inc.) and 1\% antibiotic-antimycotic. Then, the cell culture media was centrifuged at $200 \mathrm{x} \mathrm{g}$ for $5 \mathrm{~min}$ at $4^{\circ} \mathrm{C}$, and the supernatant was harvested after a transient transfection (Lipofectamine 2000; Thermo Fisher Scientific, Inc.) for 6 days and purified with a Protein A column (Cytiva). The purified protein was separated via $12 \%$ SDS-PAGE and visualized by staining with $0.1 \%$ Coomassie brilliant blue R250 at room temperature for $1 \mathrm{~h}$.

ELISA. ELISA was used to assay the affinity of human anti-TLR4 IgG2. Briefly, 96-well plates were precoated with $50 \mathrm{ng}$ TLR4 antigen (R\&D Systems, Inc.) per well in coating buffer (50 mM sodium carbonate buffer, $\mathrm{pH}$ 9.6) overnight at $4^{\circ} \mathrm{C}$. After blocking with $5 \%$ non-fat milk at room temperature for $1 \mathrm{~h}, 100 \mu \mathrm{l}$ human anti-TLR4 IgG2 at different concentrations was added to the wells (1:2 serial dilution; 3 wells per dilution) for incubation at $37^{\circ} \mathrm{C}$ for $1 \mathrm{~h}$. The plates were washed three times with $250 \mu \mathrm{l}$ PBS containing $0.1 \%$ Tween 20. Horseradish peroxidase (HRP)-conjugated goat anti-human IgG (1:3,000; cat. no. AP113P; Sigma-Aldrich; Merck KGaA) was then added. The absorbance values of the wells were determined at $450 \mathrm{~nm}$ and analyzed by GraphPad Prism software version 5.0 (GraphPad Software Inc.). The negative control comprised PBS $(10 \mathrm{mM})$. The experiment was performed in triplicate.

Affinity and kinetic assay of human anti-hTLR4 IgG2. Affinity and kinetic assays of human anti-hTLR4 IgG2 were performed using a BLItz system (ForteBio, Inc.). TLR4 was diluted to $50 \mathrm{ng} / \mu \mathrm{l}$ using PBS and then loaded to the biosensor (cat. no. 18-5012; ForteBio, Inc.), while the anti-TLR4 IgG2 was diluted in different concentrations (100-1,600 nM). The association time was $120 \mathrm{sec}$ and the dissociation time was $120 \mathrm{sec}$. Then, BLItz Pro 1.0 software (ForteBio, Inc.) was used to analyze sensograms.

Fluorescence-activated cell sorting. Each group of MPM $\left(1 \times 10^{6}\right.$ cells) was pretreated with $5 \mathrm{ng} / \mu 1$ human anti-TLR4 IgG2 at $37^{\circ} \mathrm{C}$ for $1 \mathrm{~h}$, washed three times with PBS and probed with FITC-conjugated anti-human $\operatorname{IgG}$ (1:1,000; cat. no. F9512; Sigma-Aldrich; Merk KGaA) at $37^{\circ} \mathrm{C}$ for $1 \mathrm{~h}$. A LSRII flow cytometer (BD Biosciences) was used to detect the fluorescence intensity of cells after washing three times with PBS.

Reverse transcription-quantitative PCR (RT-qPCR) analysis. To optimize the pretreatment concentration, MPM were cultured in 24 -well plates $\left(5 \times 10^{5}\right.$ cells/well), pretreated with human anti-TLR4 IgG2 at different concentrations $(1,5$ and $10 \mathrm{ng} / \mu \mathrm{l})$ at $37^{\circ} \mathrm{C}$ for $2 \mathrm{~h}$ and then stimulated with $1 \mathrm{ng} / \mu \mathrm{l}$ LPS at $37^{\circ} \mathrm{C}$ for $4 \mathrm{~h}$. The optimum concentration of human 
anti-TLR4 $\operatorname{IgG} 2(5 \mathrm{ng} / \mu \mathrm{l})$ was used for subsequent analyses. After stimulation, total RNA was extracted using the RNAfast200 kit (cat. no. 220010; ShanghaiFastagen Biotech Co., Ltd.) and RT RNA to cDNA $\left(37^{\circ} \mathrm{C}\right.$ for $\left.15 \mathrm{~min}\right)$ using the PrimeScript RT Master Mix kit (cat. no. RR036A; Takara Bio, Inc.). RT-qPCR was performed using SYBR-Green I kit (cat. no. DRR041A; Takara Bio, Inc.) under the following conditions: Initial denaturation at $95^{\circ} \mathrm{C}$ for $30 \mathrm{sec}$, followed by 40 cycles of $95^{\circ} \mathrm{C}$ for $5 \mathrm{sec}, 58^{\circ} \mathrm{C}$ for $10 \mathrm{sec}$ and $72^{\circ} \mathrm{C}$ for $30 \mathrm{sec}$ and an end-up synthesis at $72^{\circ} \mathrm{C}$ for $30 \mathrm{sec}$. The relative expressions of cytokines were normalized to those of $\beta$-actin, using the $2^{-\Delta \Delta \mathrm{Cq}}$ method (19). The primers, as previously described, were shown in Table I (20).

Western blot analysis. In order to analyze the inhibitory effect of human anti-TLR4 IgG2 on TLR4 signal transduction, western blotting analysis of phosphorylation levels of the $\mathrm{NF}-\kappa \mathrm{B}$, mitogen-activated protein kinase (MAPK) and IRF-3 pathways was performed as previously described (20). The mouse macrophages, cultured in 6 -well plates $\left(10^{6}\right.$ cells per well), were pre-incubated with the human anti-TLR4 IgG2 $(5 \mathrm{ng} / \mu \mathrm{l})$ at $37^{\circ} \mathrm{C}$ for $2 \mathrm{~h}$ and induced with LPS $(1 \mathrm{ng} / \mu \mathrm{l})$ at $37^{\circ} \mathrm{C}$ for 0,30 or $60 \mathrm{~min}$. Cells were lysed in a RIPA lysis buffer supplemented with protein inhibitor cocktail (Sigma-Aldrich; Merck KGaA). Lysates were mixed and centrifuged at $12,000 \mathrm{x} \mathrm{g}$ for $15 \mathrm{~min}$ at $4^{\circ} \mathrm{C}$. A total of $30 \mu \mathrm{g}$ protein/lane was then loaded onto an SDS-PAGE gel (12\% resolving gel) and electrotransferred onto a nitrocellulose membrane after determining the protein concentration by BCA protein assay kit (cat. no. 23225; Thermo Fisher Scientific Inc.). After blocking with $5 \%$ non-fat milk in $\operatorname{TBST}(0.1 \%$ Tween 20$)$ at $37^{\circ} \mathrm{C}$ for $1 \mathrm{~h}$, the membranes were incubated with primary antibodies (anti-p-p38, anti-p38, anti-p-p65, anti-p65, anti-p-JNK, anti-JNK, anti-p-ERK,

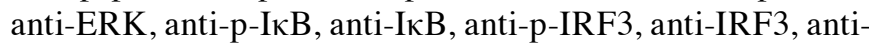
p-IKK, anti-IKK and anti- $\beta$-actin antibody) diluted at 1:1,000 with $5 \%$ non-fat milk in TBST overnight at $4^{\circ} \mathrm{C}$. Membranes were then washed three times with TBST and probed with HRP-conjugated secondary antibodies $(1: 2,000$; cat. no. 7074; Cell Signaling Technology, Inc.) in 5\% non-fat milk in TBST at room temperature for $1 \mathrm{~h}$. Then, the bands were visualized by an enhanced chemiluminescence kit (cat. no. 1805001; Tanon Science and Technology Co., Ltd.). The relative protein expression levels were analyzed using Gel-Pro-analyzer software 4.0 (Media Cybernetics, Inc.).

In vivo neutralization assay. To determine the protective efficacy of human anti-TLR4 IgG2 in the cecal ligation and puncture (CLP) model (21), female C57BL/6 mice $(n=39)$ were randomly divided into three experimental groups with 13 mice each. All mice were housed in $12: 12 \mathrm{~h} \mathrm{light/dark}$ cycle at $22^{\circ} \mathrm{C}$ and free access to food and water. Mice in Group $\mathrm{L}+\mathrm{A}(\mathrm{L}$, LPS; A, human anti-TLR4 IgG2) were passively immunized with $15 \mu \mathrm{g} / \mathrm{g}$ body weight anti-TLR4 IgG2 $2 \mathrm{~h}$ before exposure to $15 \mu \mathrm{g} / \mathrm{g}$ body weight LPS to assess its prophylactic potential. Mice in Group L were injected with $15 \mu \mathrm{g} / \mathrm{g}$ body weight LPS, and mice in Group A were injected with $15 \mu \mathrm{g} / \mathrm{g}$ body weight human anti-TLR4 IgG2. For this experiment, human anti-TLR4 IgG2 was injected intravenously, whereas LPS was injected peritoneally. Animals were observed continuously for
Table I. Primers for mouse inflammatory factors used in reverse transcription-quantitative PCR.

\begin{tabular}{ll}
\hline Gene name & \multicolumn{1}{c}{ Primers (5'-3') } \\
\hline$T N F-\alpha$ & F: GACGTGGAACTGGCAGAAGAG \\
& R: TTGGTGGTTTGTGAGTGTGAG \\
$I F N-\beta$ & F: CAGCTCCAAGAAAGGACGAAC \\
& R: GGCAGTGTAACTCTTCTGCAT \\
$I L-6$ & F:TAGTCCTTCCTACCCCAATTTCC \\
& R: TTGGTCCTTAGCCACTCCTTC \\
& F: AGTGTGACGTTGACATCCGT \\
& R: GCAGCTCAGTAACAGTCCGC
\end{tabular}

TNF- $\alpha$, tumor necrosis factor- $\alpha$; IFN- $\beta$, Interferon- $\beta$; IL- 6 , interleukin-6; F, forward; R, reverse.

the first $4 \mathrm{~h}$, at $8 \mathrm{~h}$ and throughout the next few days, which was followed by forth-daily assessment for 1 week.

Statistical analysis. Multiple comparisons were determined by one-way ANOVA with the Tukey's multiple comparison test. Comparisons between two groups were analyzed by independent samples t-test. The survival analysis was performed by Kaplan-Meier estimates. Data are presented as the mean \pm SD. $\mathrm{P}<0.05$ was considered to indicate a statistically significant difference.

\section{Results}

Construction and expression of human anti-TLR4 IgG2. Following seven rounds of affinity panning, 11 of the 60 candidate phage clones showed a strong positive signal. After inspecting the sequence in the VBASE2 database, a $\kappa$-type light chain was identified. It was found that the variable heavy $(\mathrm{VH})$ and variable light (VL) chains were amplified up to $\sim 350 \mathrm{bp}$ each (Fig. 1A), and the synthetized $\mathrm{H}$ and $\mathrm{L}$ chains with constant regions of human IgG2 (Fig. 1B) were each separately inserted into the eukaryotic expression vector pMH3. Moreover, eukaryotic expression vectors harboring human anti-TLR4 IgG2 (pMH3-anti-hTLR4-IgG2-H and pMH3-anti-hTLR4-IgG2-L) were successfully constructed (Fig. 1C).

The recombinant expression vector was transfected into $\mathrm{CHO}$ cells, which were cultured for 6 days. Cells were centrifuged and the supernatant was purified with a Protein A affinity column and examined via SDS-PAGE, followed by Coomassie Brilliant Blue staining (Fig. 1D). It was identified that the purification efficiency was $\sim 95 \%$ with $2.5 \mathrm{mg} / \mathrm{ml}$ human anti-TLR4 IgG2.

Verification of specific binding of human anti-TLR4 IgG2 to TLR4. The present study determined whether human anti-TLR4 IgG2 can specifically and selectively bind to human TLR4 using ELISA. Gradient dilutions of human anti-TLR4 IgG2 were prepared for ELISA and it was found that this antibody can specifically bind to TLR4 in a dose-dependent manner (Fig. 2A). The antigen-antibody affinity constant was assessed to analyze the binding affinity of human anti-TLR4 

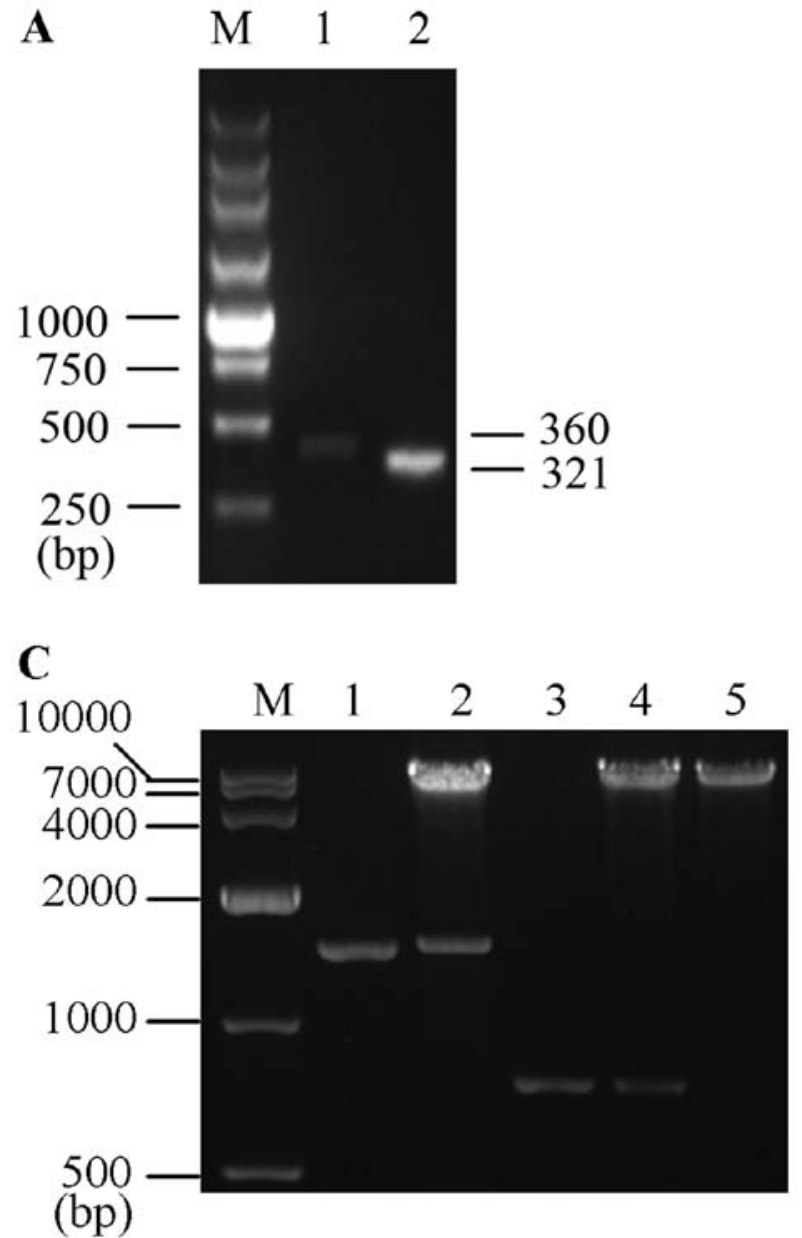

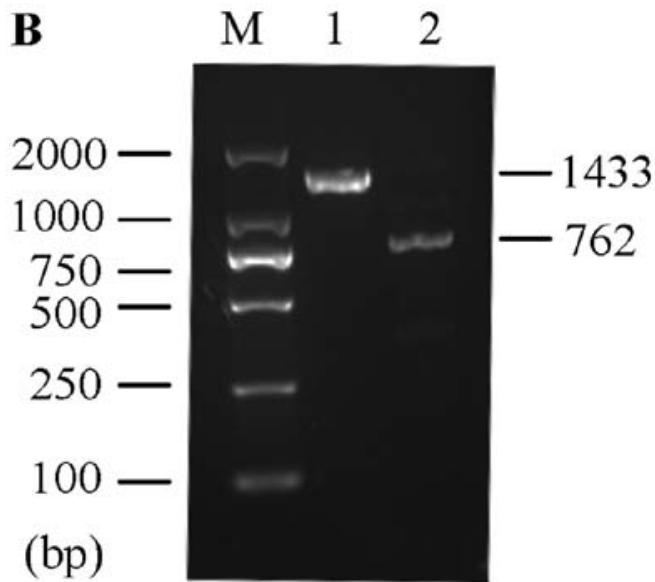

D

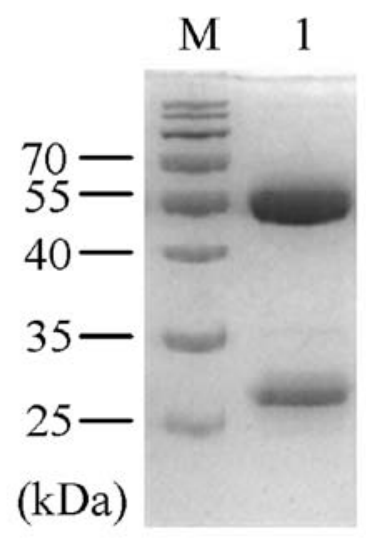

Figure 1. Preparation of human anti-TLR4 IgG2. (A) Anti-TLR4 IgG2-VH and anti-TLR4 IgG2-VL variable regions were screened from a human Fab phage library. M, 250 bp DNA ladder Marker. Lane 1, anti-TLR4 IgG2-VH variable region (360 bp). Lane 2, anti-TLR4 IgG2-VL variable region (321 bp). (B) Amplification products of the synthetized anti-TLR4 IgG2-H and anti-TLR4 IgG2-L chains. M, DL2000 DNA Marker. Lane 1, anti-TLR4 IgG2-H (1,433 bp). Lane 2, anti-TLR4 IgG2-L (762 bp). (C) The two recombinant eukaryotic expression vectors (pMH3-anti-hTLR4-IgG2-H and pMH3-anti-hTLR4-IgG2-L) were double-digested with EcoR I and Not I. M, DL10000 DNA Marker. Lane 1, anti-TLR4 IgG2-H. Lane 2, double-digested pMH3-anti-hTLR4-IgG2-H. Lane 3, anti-TLR4 IgG2-L. Lane 4, double-digested pMH3-anti-hTLR4-IgG2-L. Lane 5, Linearized pMH3. (D) SDS-PAGE identified the purify of human anti-TLR4 IgG2. M, A protein Marker. Lane 1, Purified human anti-TLR4 IgG2. TLR4, Toll-like receptor 4; L, light chain; H, heavy chain.

IgG2 to TLR4. Data obtained from BLItz system analysis had an equilibrium dissociation constant (KD) of $8.713 \times 10^{-10} \mathrm{M}$ (Fig. 2B), indicating that human anti-TLR4 IgG2 selectively and effectively bound to TLR4.

The binding ability of human anti-TLR4 IgG2 was further assessed via flow cytometric analysis of TLR4-positive MPM. Compared with the untreated control group, specific binding of the human anti-TLR4 IgG2 to TLR4 reached $\sim 66 \%$ (Fig. 2C), suggesting that human anti-TLR4 $\mathrm{IgG} 2$ effectively binds to TLR4 on the mouse cell surface.

Human anti-TLR4 IgG2 inhibits LPS-induced production of inflammatory cytokines in vitro. To determine the optimal human anti-TLR4 IgG2 concentration that can inhibit LPS-stimulated MPM, the optimal concentrations of human anti-TLR4 IgG2 and LPS were examined. LPS was used at concentrations ranging from $0.01-1 \mathrm{ng} / \mu \mathrm{l}$, and it was demonstrated that the mRNA expression levels of TNF- $\alpha$ and IFN- $\beta$ were increased in a concentration-dependent manner compared with the $\mathrm{L}+\mathrm{A}$ group (Fig. S1 A and B). In addition, it was found that $1 \mathrm{ng} / \mu 1 \mathrm{LPS}$ induced significant inflammation, on which the human anti-TLR4 IgG2 showed a higher inhibition efficiency. Furthermore, compared with $1 \mathrm{ng} / \mu \mathrm{l}$ human anti-TLR4 IgG2, a concentration of $5 \mathrm{ng} / \mu \mathrm{l}$ showed improved inhibition efficiency on IFN- $\beta$ and TNF- $\alpha$ mRNA expression levels (Fig. 3). However, $10 \mathrm{ng} / \mu 1$ human anti-TLR4 IgG2 did not have a higher performance compared with the concentration of $5 \mathrm{ng} / \mu \mathrm{l}$. Moreover, treatment with $5 \mathrm{ng} / \mu \mathrm{l}$ human anti-TLR4 IgG 2 reduced TNF- $\alpha$, IFN- $\beta$ and IL- 6 expression levels by approximately 50, 90 and 40\%, respectively, compared with levels after LPS treatment (Fig. 3). Therefore, human anti-TLR4 IgG2 and LPS concentrations of 5 and $1 \mathrm{ng} / \mu 1$, respectively, were used in the subsequent experiments.

To assess whether human anti-TLR4 $\mathrm{IgG} 2$ reduces the production of LPS-induced inflammatory cytokines, the mRNA expression levels of TNF- $\alpha$, IFN- $\beta$ and IL- 6 were examined at different time points. MPM were pretreated with $5 \mathrm{ng} / \mu \mathrm{l}$ human anti-TLR4 IgG 2 for $2 \mathrm{~h}$ and induced with $1 \mathrm{ng} / \mu \mathrm{l}$ LPS for 2,4 and $8 \mathrm{~h}$. It was demonstrated that TNF- $\alpha$, IFN- $\beta$ and IL- 6 were significantly upregulated in LPS-induced groups compared with those in the untreated controls; however, these were significantly downregulated after pretreatment with 

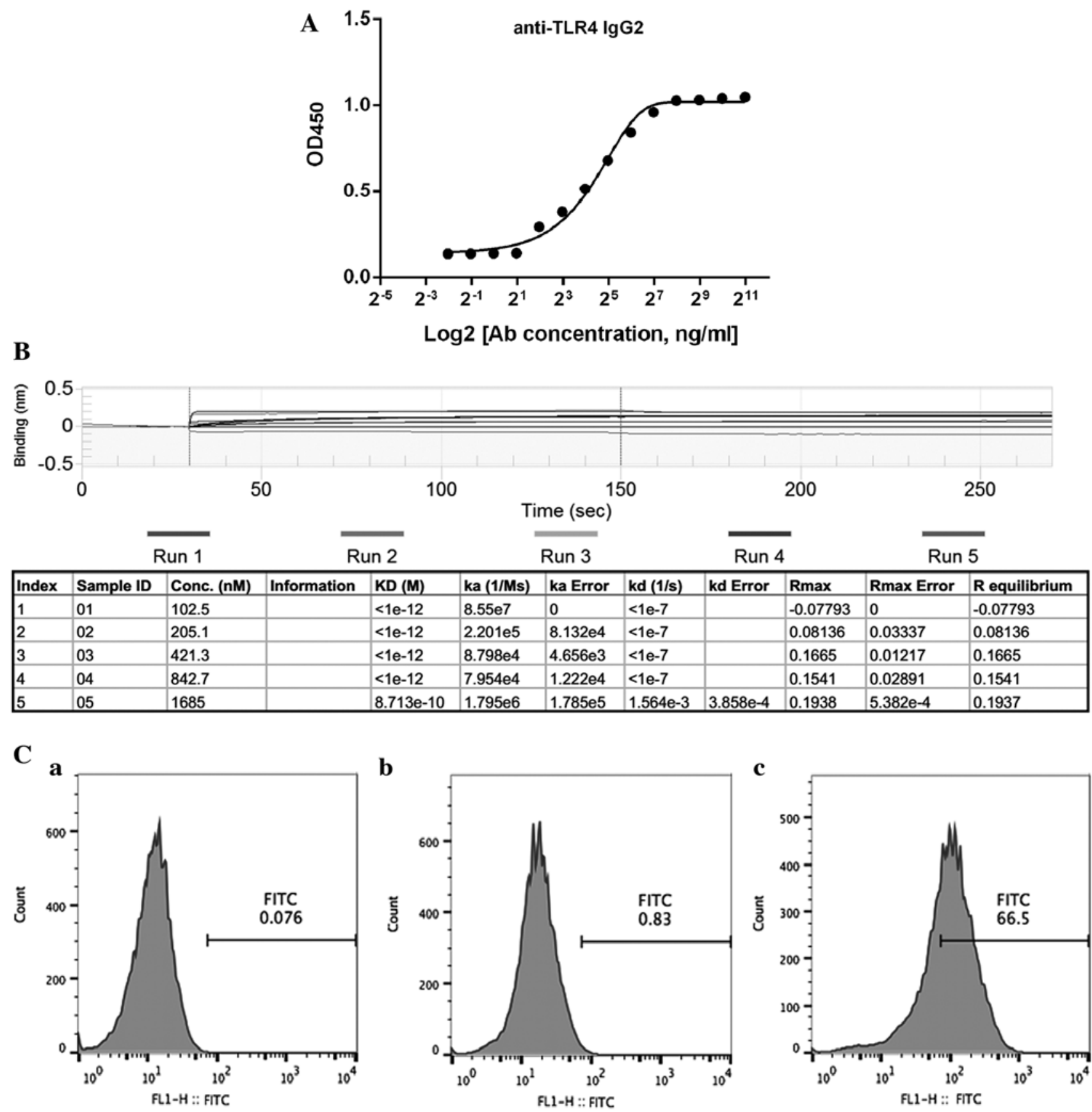

Figure 2. Human anti-TLR4 IgG2 specifically recognizes TLR4 with high affinity. (A) ELISA results. TLR4 was used to coat ELISA plates. The wells were incubated with serial dilutions of human anti-TLR4 IgG2. The specific binding of human anti-TLR4 IgG2 and TLR4 was concentration-dependent. (B) A BLItz System was used to determine the binding affinity of TLR4. TLR4 affinity and kinetics assays yielded five curves with the concentrations of human anti-TLR4 IgG2 ranging from 100-1,600 nM. Equilibrium dissociation constant $=8.713 \times 10^{-10} \mathrm{M}$ with TLR4. (C) Affinity of human anti-TLR4 IgG2 for TLR4 was quantified via flow cytometry analysis. (a) Blank; (b) group treated without human anti-TLR4 IgG2; (c) group treated with human anti-TLR4 IgG2. OD450, optical density at $450 \mathrm{~nm}$; TLR4, Toll-like receptor 4.

human anti-TLR4 IgG2 (Fig. 4). Furthermore, the inhibition of human anti-TLR4 IgG2 was most potent at $4 \mathrm{~h}$ and was 50-60\%.

Human anti-TLR4 IgG2 inhibits phosphorylation levels of TLR4 signaling after LPS stimulation. To investigate the inhibition of human anti-TLR4 IgG2 on LPS-induced TLR4 signaling, western blotting was used to analyze the phosphorylation of the NF- $\kappa$ B, MAPK and IRF-3 signaling pathways, which are downstream effectors of the TLR4 pathway. After treatment with LPS, the phosphorylation of p65, p38, JNK, ERK, I $\mathrm{B}, \mathrm{IKK}$ and IRF-3 increased, but decreased after pretreatment with $5 \mathrm{ng} / \mu 1$ human anti-TLR4 IgG2 (Figs. 5-7). Thus, these results indicated that human anti-TLR4 IgG2 inhibited LPS-induced inflammatory responses in MPM by blocking TLR4.

Human anti-TLR4 IgG2 protects mice from LPS-induced sepsis in vivo. An in vivo protection assay was carried out in the CLP model. After LPS administration, the mice treated 

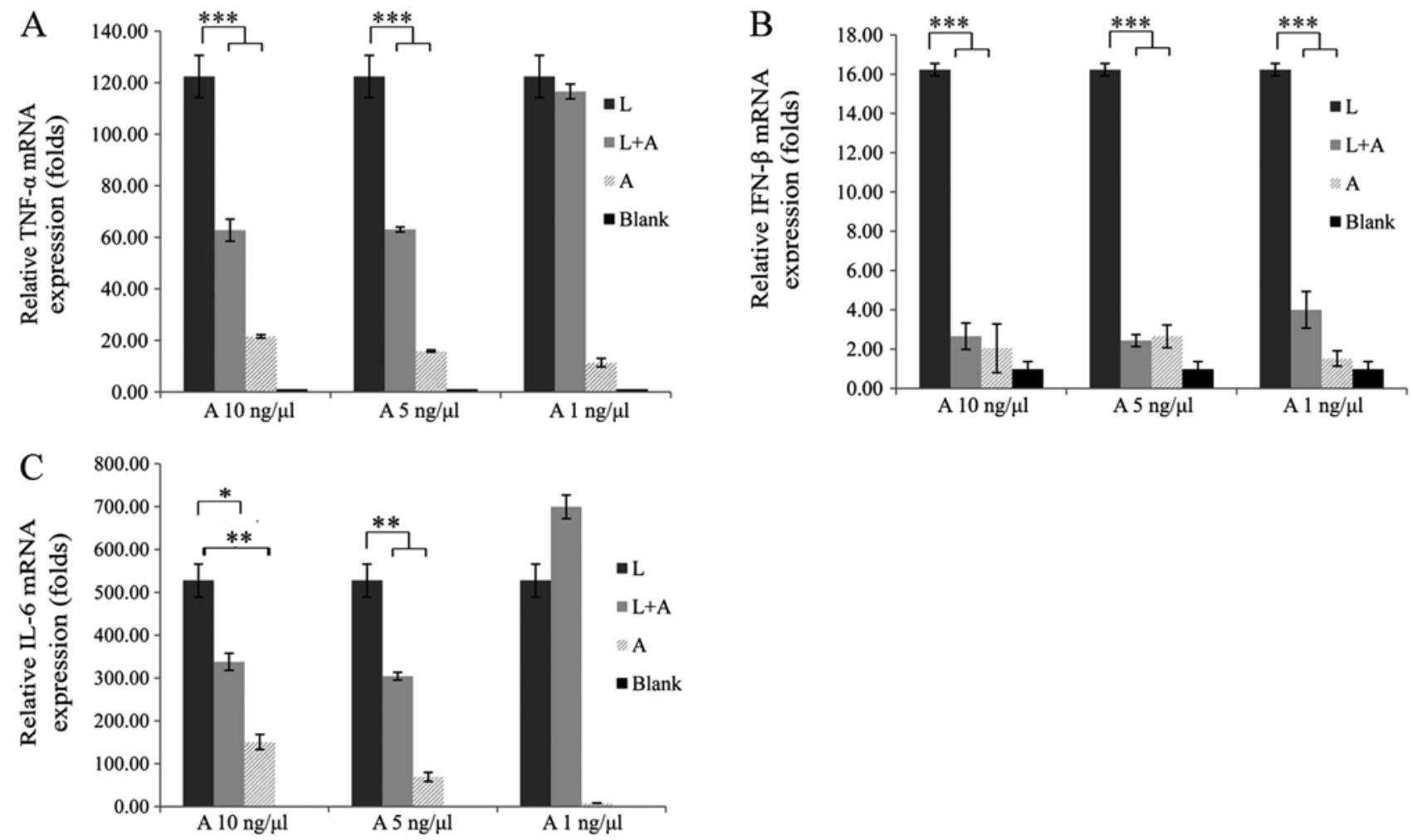

Figure 3. Inhibitory effects of different concentrations of human anti-TLR4 IgG2 on LPS-induced macrophages. Macrophages were preincubated with different concentrations $(1,5$ and $10 \mathrm{ng} / \mu \mathrm{l})$ of human anti-TLR4 IgG2 for $2 \mathrm{~h}$, and then induced with $1 \mathrm{ng} / \mu 1 \mathrm{LPS}$ for $4 \mathrm{~h}$. mRNA expression levels of (A) TNF- $\alpha$, (B) IFN- $\beta$ and (C) $I L-6$ were determined via reverse transcription-quantitative PCR and normalized to that of the internal control, $\beta$-actin. The optimal concentration of human anti-TLR4 IgG2 was $5 \mathrm{ng} / \mu \mathrm{l}$. All experiments were performed independently $\geq 3$ times. Data are presented as the mean $\pm \mathrm{SD}$. $\mathrm{N}=3$. ${ }^{*} \mathrm{P}<0.05,{ }^{* *} \mathrm{P}<0.01$, ${ }^{* * * *} \mathrm{P}<0.001$ vs. LPS control. LPS, lipopolysaccharide; TLR4, Toll-like receptor 4; L, LPS; A, human anti-TLR4 IgG2; IL, interleukin; IFN- $\beta$, interferon- $\beta$; TNF- $\alpha$, tumor necrosis factor- $\alpha$.

with PBS in the control group died within $35 \mathrm{~h}$. Moreover, in the Group L + A receiving the antibody, human anti-TLR4 $\mathrm{IgG} 2$ protected mice from LPS challenge with a survival rate of $40 \%$ and significantly increased the survival time, compared with the Group L (Fig. 8). Furthermore, the present study examined the serum levels of inflammatory factors by ELISA. It was identified that treatment with human anti-TLR4 IgG2 reduced LPS-initiated inflammatory responses, as it reduced TNF- $\alpha$, IFN- $\beta$ and IL- 6 levels by $\sim 80,75$ and $60 \%$ at $4 \mathrm{~h}$ after LPS injection, respectively (Fig. S2). Collectively, these results were consistent with those from the in vitro inhibition assay.

\section{Discussion}

Excessive host responses to LPS can lead to systemic inflammatory conditions, including sepsis and fatal septic shock (22-24). The mortality rate of severe sepsis can reach $30-50 \%$ worldwide, possibly due to the lack of efficient therapies (22-24). Previous findings have confirmed the role of inflammatory pathways stimulated by the interaction between TLR4 and LPS (13); therefore, blocking of LPS-TLR4 signaling is important.

The present study extracted an anti-TLR4 Fab from a human phage library and transformed it to IgG2 with an affinity of $8.713 \times 10^{-10} \mathrm{M}$, which has stronger affinity to TLR4 compared with the Fab region alone. The eukaryotic expression vector pMH3-hTLR4-IgG2 was successfully constructed and using a BLItz system and ELISA, the specific binding ability of the human anti-TLR4 IgG2 to TLR4 was assessed. The present results indicated that the $\mathrm{H}$ and $\mathrm{L}$ chains of human anti-TLR4 $\mathrm{IgG} 2$ were efficiently assembled into the active form, and the approaches to prepare $\mathrm{mAb}$ did not change the specificity of the human anti-TLR4 IgG2.

LPS increases the secretion of numerous inflammatory cytokines by activating the phosphorylation of the TLR4-mediated NF- $\kappa B$, MAPK and IRF3 pathways, and also elevates the production of $\mathrm{T}$ proinflammatory cytokines $(11-13,25)$. Thus, the present study evaluated human anti-TLR 4 IgG 2 by measuring TNF- $\alpha$, IFN- $\beta$ and IL- 6 levels, which are involved in the MyD88 pathway, after LPS stimulation. The results showed that human anti-TLR4 IgG2 at $5 \mathrm{ng} / \mu 1$ was sufficient for blocking TLR4 on the surface of MPM, and did not show a higher inhibitory effect at an increased concentration (10 $\mathrm{ng} / \mu \mathrm{l})$. Moreover, RT-qPCR results identified a significant increase in LPS-induced production of TNF- $\alpha$, IFN- $\beta$ and IL- 6 mRNA expression levels, but this production decreased after pretreatment with human anti-TLR4 IgG2. Western blotting results demonstrated that LPS-stimulated phosphorylation of p65, p38, JNK, ERK, I $\mathrm{B} \alpha, \mathrm{IKK} \alpha / \beta$ and IRF3. However, these results were reversed by preincubation with human anti-TLR4 $\mathrm{IgG} 2$, which was consistent with the decreased expression levels of proinflammatory cytokines. In addition, given the high homology between mice and humans, an in vivo neutralization assay as performed using the mouse CLP model in which LPS was injected peritoneally. However, as 
A
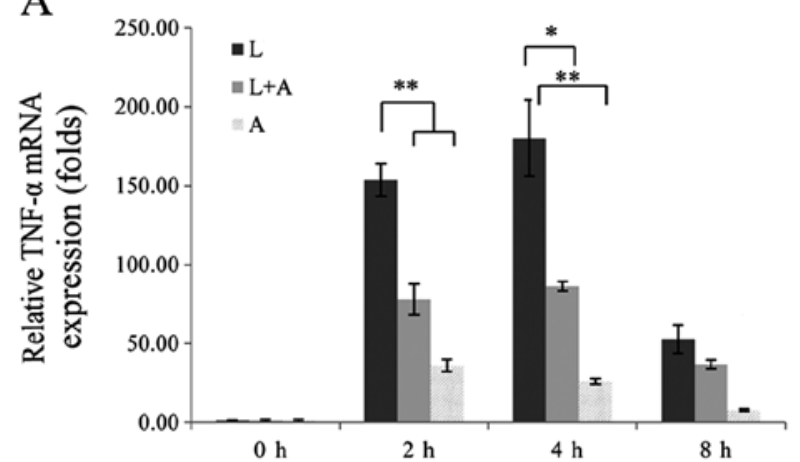

B

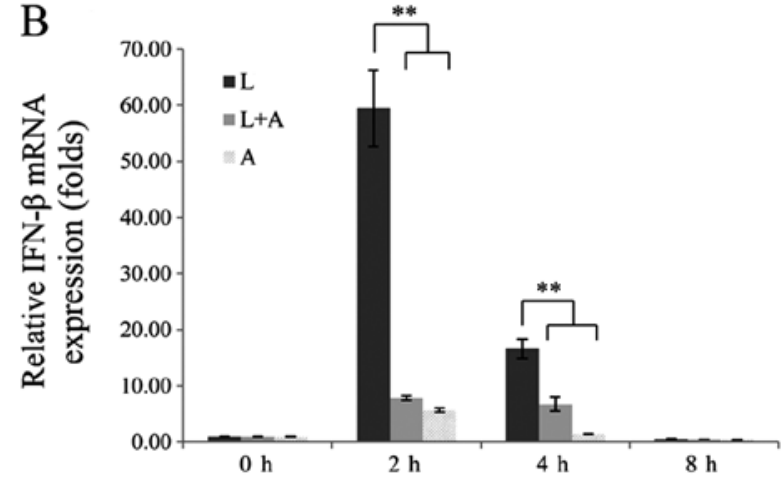

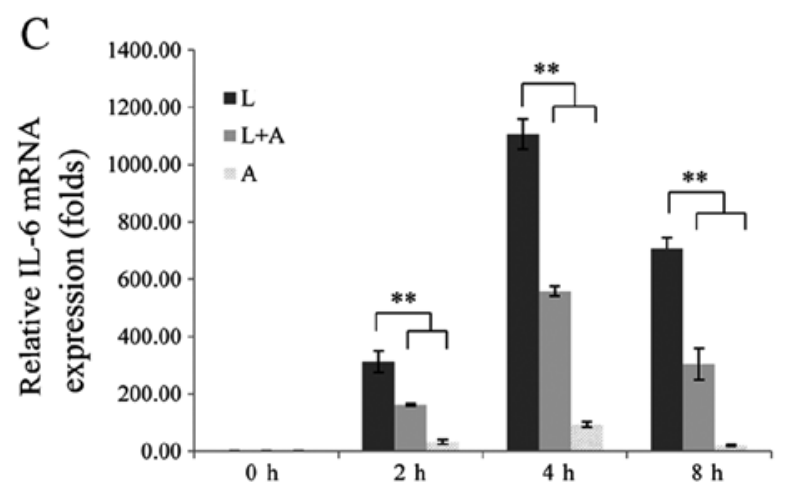

Figure 4. Human anti-TLR4 IgG2 inhibits LPS-induced production of inflammatory cytokines in mouse macrophages. (A) $T N F-\alpha$, (B) $I F N-\beta$ and (C) $I L-6$ expression levels were quantified via reverse transcription-quantitative PCR and normalized to the internal control, $\beta$-actin. All experiments were performed independently $\geq 3$ times. Data are presented as the mean $\pm \mathrm{SD}$. $\mathrm{N}=3$. ${ }^{*} \mathrm{P}<0.05,{ }^{* *} \mathrm{P}<0.01$, vs. LPS control. LPS, lipopolysaccharide; TLR4, Toll-like receptor 4 ; L, LPS; A, human anti-TLR4 IgG2; IL, interleukin; IFN- $\beta$, interferon- $\beta$; TNF- $\alpha$, tumor necrosis factor- $\alpha$.
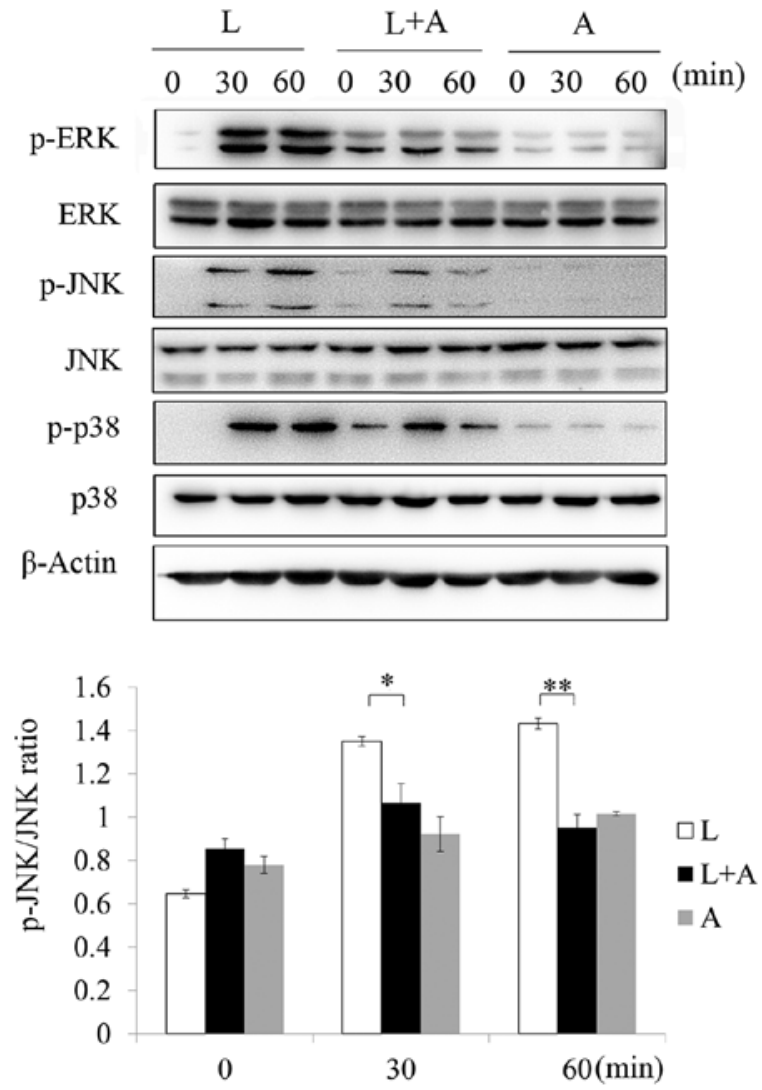

Figure 5. Human anti-TLR4 IgG2 activates the MAPK signal pathway after LPS stimulation. Cells were pretreated with human anti-TLR4 IgG2 (5 ng/ $\mu 1)$ for $2 \mathrm{~h}$ and further incubated in the presence or absence of LPS $(1 \mathrm{ng} / \mu \mathrm{l})$ for 0,30 and $60 \mathrm{~min}$. After immunoblotting, phospho-specific antibodies were used to probe the regions containing p-ERK1/2, p-JNK1/2 and p-p38. $\beta$-actin was used as the internal loading control. ${ }^{*} \mathrm{P}<0.05,{ }^{* * *} \mathrm{P}<0.01,{ }^{* * * *} \mathrm{P}<0.001$ vs. LPS group. LPS, lipopolysaccharide; TLR4, Toll-like receptor 4; L, LPS; A, human anti-TLR4 IgG2; p-, phosphorylated. 


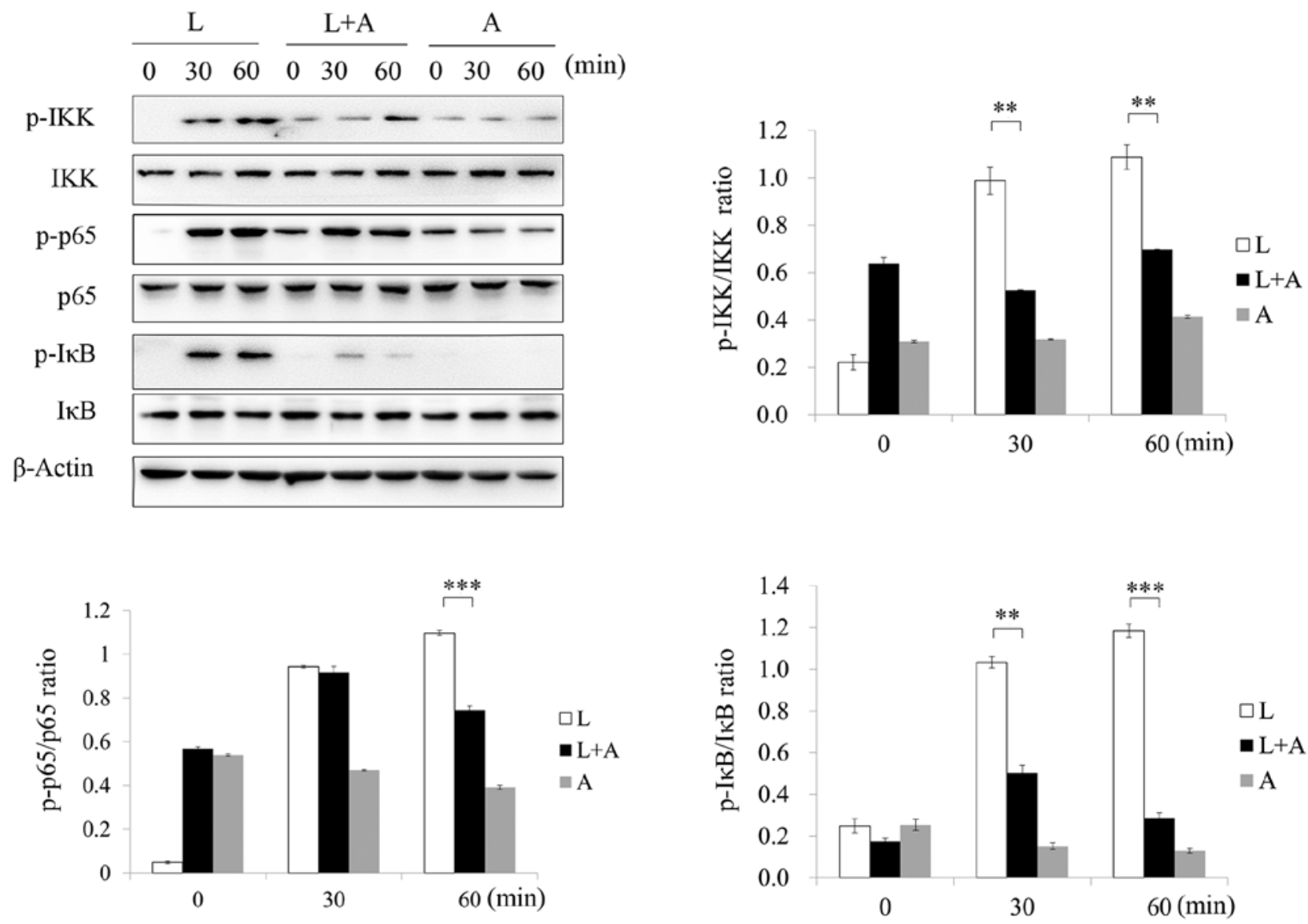

Figure 6. Human anti-TLR4 IgG2 activates the NF- $\mathrm{B}$ signaling pathway after LPS stimulation. Cells were pretreated with human anti-TLR4 IgG2 (5 ng/ $\mu$ l) for $2 \mathrm{~h}$ and further incubated in the presence or absence of LPS $(1 \mathrm{ng} / \mu \mathrm{l})$ for 0,30 and $60 \mathrm{~min}$. After immunoblotting, phospho-specific antibodies were used to probe the regions containing p-IKK, p-IкB and p-p65. $\beta$-actin was used as the internal loading control. ${ }^{* *} \mathrm{P}<0.01,{ }^{* * *} \mathrm{P}<0.001$ vs. LPS group. LPS, lipopolysaccharide; TLR4, Toll-like receptor 4; L, LPS; A, human anti-TLR4 IgG2; p-, phosphorylated.
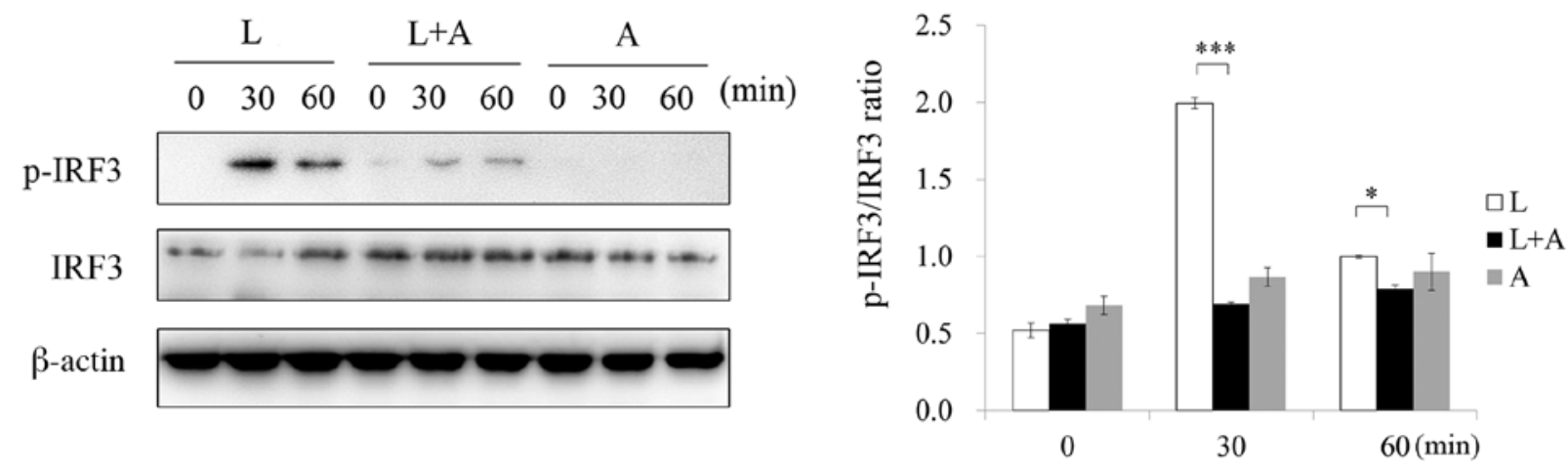

Figure 7. Human anti-TLR4 IgG2 activates IRF-3 after LPS stimulation. Cells were pretreated with human anti-TLR4 IgG2 (5 ng/ $\mu$ l) for $2 \mathrm{~h}$ and further incubated in the presence or absence of LPS $(1 \mathrm{ng} / \mu \mathrm{l})$ for 0,30 and $60 \mathrm{~min}$. The phospho-specific antibody was used to detect phosphorylation level of IRF-3. $\beta$-actin was used as the internal loading control. " $\mathrm{P}<0.05,{ }^{* * *} \mathrm{P}<0.001$ vs. LPS group. LPS, lipopolysaccharide; TLR4, Toll-like receptor 4; L, LPS; A, human anti-TLR4 IgG2; p-, phosphorylated.

the half-life of antibody is short, mice were immunized via intravenous injection to increase the absorption rate. It was found that human anti-TLR4 IgG2 efficiently protected mice from LPS challenge with a survival rate of $40 \%$ and inhibited LPS-induced sepsis in mice by decreasing serum levels of proinflammatory cytokines. Thus, it was speculated that human anti-TLR4 IgG2 could rescue mice from severe sepsis. However, while this mouse model is used for several purposes, such as for investigating pathogenic mechanisms and evaluating new therapeutic approaches (26-28), individual gene activation in humans may not necessarily predicted by the ortholog in the corresponding mouse model (29), which is a limitation to the neutralization assay. In addition, the experiments performed in mouse macrophages do not completely mimic human inflammatory responses (29-32). Thus, further studies are required to assess the inhibitory effects of human 


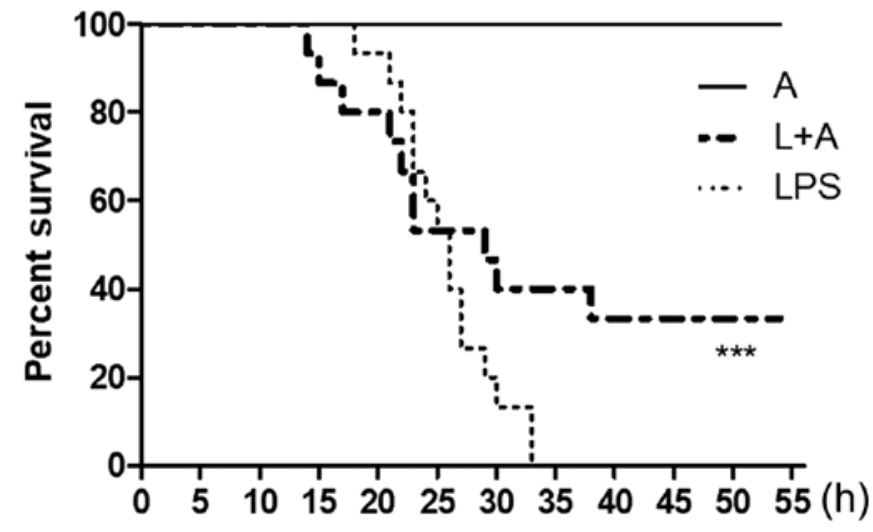

Log-rank: $P<0.0001$

Figure 8. Human anti-TLR4 IgG2 protects mice from LPS-induced lethal sepsis. Mice were intravenously injected with human anti-TLR4 IgG2 $(15 \mu \mathrm{g} / \mathrm{g})$ or equal dose of PBS at $2 \mathrm{~h}$ before exposure to LPS $(15 \mu \mathrm{g} / \mathrm{g})$. The number of mice surviving the challenge was shown. $\mathrm{N}=13 .{ }^{* * *} \mathrm{P}<0.001$ vs. LPS group. LPS, lipopolysaccharide; TLR4, Toll-like receptor 4; L, LPS; A, human anti-TLR4 IgG2.

anti-TLR4 IgG2 for the treatment of infection-associated immune dysfunction in humans.

Previous studies have been aimed at evaluating TLR4 inhibition by targeted small-molecule compounds or antibodies for the therapy of multiple inflammatory responses (33-37). In addition to the human anti-TLR4 IgG2 designed in the present study, several mAbs against TLR4 have been reported, which can be divided into two categories. Firstly, agonistic mAbs, such as UT12 and Sa15-21, which induce NF- $\kappa$ B activation and protect mice from subsequent lethal LPS challenges $(36,37)$; this phenomenon is called LPS tolerance. However, UT12 is significantly distinguished from Sa15-21 as the latter enhances LPS-induced TNF- $\alpha$ production, while Sa15-21 alone induces minimal TNF- $\alpha$ production (36). The other category is antagonistic $m$ Abs, such as MTS510, which inhibit LPS-induced NF- $\kappa$ B activation in TLR4-expressing cells (34). The human anti-TLR4 IgG2 designed in the present study belongs to the second category. Moreover, there are two advantages in the application of the human anti-TLR4 IgG2. Firstly, previous reported antibodies are mouse mAbs or humanized murine mAbs (20,34,36-38), and these antibodies contain some non-human components that could cause antigen-reactive responses. Furthermore, the human anti-TLR4 IgG2 used in the present study was a complete human antibody, without any potential to elicit $\mathrm{mAb}$ production in humans. Moreover, human anti-TLR4 IgG2 was produced using a eukaryotic expression system that had post-translational modification capabilities, while also eliminating the effect of Escherichia coli endotoxin, which is prevalent in anti-TLR4-Fab produced in prokaryotic expression systems $(20,38)$.

Previous findings have characterized the three-dimensional structures of LPS receptors (39-42). It has also been reported that the LBP binds firstly to LPS and presents it to CD14, and then CD14 transfers LPS to the TLR4/MD2 complex to form the M-shaped TLR4/MD2/LPS complex dimer (40). The TIR domains of TLR4 are located in close spatial contiguity upon dimer formation, activating downstream signaling molecules and promoting the secretion of inflammatory cytokines $(40,41)$. Therefore, it was speculated that the human anti-TLR4 IgG2 may prevent the interaction of MD2 with TLR4, thus blocking LPS-induced TLR4 signal pathway transduction. However, the protective mechanism of the human anti-TLR4 IgG2 requires further investigation.

In conclusion, the present study established a full human anti-TLR4 IgG2 that bound specifically to TLR4 with high affinity, inhibited the TLR4/MAPKs/NF- $\kappa$ B signaling pathway and reduced the production of downstream inflammatory mediators, such as TNF- $\alpha$, IL- 6 and IFN- $\beta$. Therefore, the specific blockade of TLR4 activation by the human anti-TLR4 IgG 2 may be promising in the treatment of infection-associated diseases in the future.

\section{Acknowledgements}

Not applicable.

\section{Funding}

This study was supported by research grants from the National Key R\&D Program of China (grant no. 2018YFC1200603), the National Natural Science Foundation of China (grant no. 31701181) and the Jiangsu Social Development Project (grant no. BE2018617).

\section{Availability of data and materials}

The datasets used and/or analyzed during the current study are available from the corresponding author on reasonable request.

\section{Authors' contributions}

YW performed most of the experiments, analyzed the data and wrote the manuscript. DG helped with the partial plasmid construction. FZ and TZ helped with the preparation of experimental samples. CY and QC helped with experimental operations. MW helped with experiment design. JZ and XZ designed the research and revised the manuscript. All authors read and approved the final manuscript.

\section{Ethics approval and consent to participate}

All animal experiments in this study were performed according to the protocols approved by the Ethics Committee of Huadong Medical Institute of Biotechniques.

\section{Patient consent for publication}

Not applicable.

\section{Competing interests}

The authors declare that they have no competing interests.

\section{References}

1. West AP, Koblansky AA and Ghosh S: Recognition and signaling by toll-like receptors. Annu Rev Cell Dev Biol 22: 409-437, 2006.

2. O'Neill LA, Bryant CE and Doyle SL: Therapeutic targeting of Toll-like receptors for infectious and inflammatory diseases and cancer. Pharmacol Rev 61: 177-197, 2009. 
3. Fairweather D and Frisanchokiss S: Mast cells and inflammatory heart disease: Potential drug targets. Cardiovasc Hematol Disord Drug Targets 8: 80-90, 2008 .

4. de Laat MA, Gruntmeir KJ, Pollitt CC, Mcgowan CM, Sillence MN and Lacombe VA: Hyperinsulinemia down-regulates TLR4 expression in the mammalian heart. Front Endocrinol (Lausanne) 5: 120, 2014.

5. Gay NJ, Symmons MF, Monique G and Bryant CE: Assembly and localization of Toll-like receptor signalling complexes. Nat Rev Immunol 14: 546-558, 2014.

6. Li H, Huang LF, Wen C, Yang ZC and Chen CY: Roles of cardiac mast cells and Toll-like receptor 4 in viral myocarditis among mice. Zhongguo Dang Dai Er Ke Za Zhi 15: 896-902, 2013 (In Chinese)

7. Yang Y, Lv J, Jiang S, Ma Z, Wang D, Hu W, Deng C, Fan C, Di S, Sun Y and Yi W: The emerging role of Toll-like receptor 4 in myocardial inflammation. Cell Death Dis 7: e2234, 2016.

8. Sternberg EM: Neural regulation of innate immunity: A coordinated nonspecific host response to pathogens. Nat Rev Immunol 6: 318-328, 2006.

9. Beutler B, Du X and Poltorak A: Identification of Toll-like receptor 4 (Tlr4) as the sole conduit for LPS signal transduction: Genetic and evolutionary studies. J Endotoxin Res 7: 277-280, 2001.

10. Tan Y and Kagan JC: A cross-disciplinary perspective on the innate immune responses to bacterial lipopolysaccharide. Mol Cell 54: 212-223, 2014.

11. Husebye H, Halaas $\varnothing$, Stenmark H, Tunheim G, Sandanger $\varnothing$, Bogen B, Brech A, Latz E and Espevik T: Endocytic pathways regulate Toll-like receptor 4 signaling and link innate and adaptive immunity. EMBO J 25: 683-692, 2006.

12. Kagan JC, Su T, Horng T, Chow A, Akira S and Medzhitov R: TRAM couples endocytosis of Toll-like receptor 4 to the induction of interferon-beta. Nat Immunol 9: 361-368, 2008.

13. Lu YC, Yeh W and Ohashi PS: LPS/TLR4 signal transduction pathway. Cytokine 42: 145-151, 2008.

14. Annane D, Bellissant E and Cavaillon JM: Septic shock. Lancet 365: 63-78, 2005.

15. Hotchkiss RS and Karl IE: The Pathophysiology and Treatment of Sepsis. N Engl J Med 348: 138-150, 2003.

16. Kaplon H and Reichert JM: Antibodies to watch in 2019. MAbs 11: 219-238, 2019.

17. Park J and Rikihisa Y: Inhibition of ehrlichia risticii infection in murine peritoneal macrophages by gamma interferon, a calcium ionophore, and concanavalin A. Infect Immun 59: 3418-3423 1991.

18. Jiao Y, Zhao P, Zhu J, Grabinski T, Feng Z, Guan X, Skinner RS, Gross MD, Hay RV, Tachibana H and Cao B: Construction of human naïve Fab library and characterization of anti-met Fab fragment generated from the library. Mol Biotechnol 31: 41-54, 2005.

19. Livak KJ and Schmittgen TD: Analysis of relative gene expression data using real-time quantitative PCR and the 2(-Delta Delta C(T)) method. Methods 25: 402-408, 2001.

20. Cai B, Wang M, Zhu X, Xu J, Zheng W, Zhang Y, Zheng F Feng $Z$ and Zhu J: The Fab fragment of a humanized anti-Toll like receptor 4 (TLR4) monoclonal antibody reduces the lipopolysaccharide response via TLR4 in mouse macrophage. Int J Mol Sci 16: 25502-25515, 2015.

21. Hubbard WJ, Choudhry M, Schwacha MG, Kerby JD, Rue LW III, Bland KI and Chaudry IH: Cecal ligation and puncture. Shock 24 (Suppl 1): S52-S57, 2005.

22. Bryant CE, Spring DR, Gangloff M and Gay NJ: The molecular basis of the host response to lipopolysaccharide. Nat Rev Microbiol 8: 8-14, 2010

23. Miller SI, Ernst RK and Bader MW: LPS, TLR4 and infectious disease diversity. Nat Rev Microbiol 3: 36-46, 2005.

24. Rosadini CV and Kagan JC: Early innate immune responses to bacterial LPS. Curr Opin Immunol 44: 14-19, 2017.
25. Lauren A, Brown AG, Samuel P and Elovitz MA: Lipopolysaccharide induces cytokine production and decreases extravillous trophoblast invasion through a mitogen-activated protein kinase-mediated pathway: Possible mechanisms of first trimester placental dysfunction. Hum Reprod 27: 61-72, 2012.

26. Davis MM: A prescription for human immunology. Immunity 29 835-838, 2008

27. Hayday AC and Peakman M: The habitual, diverse and surmountable obstacles to human immunology research. Nat Immunol 9: 575-580, 2008

28. Woodcock J and Woosley R: The FDA critical path initiative and its influence on new drug development. Annu Rev Med 59: 1-12, 2008.

29. Seok J, Warren HS, Cuenca AG, Mindrinos MN, Baker HV, Xu W, Richards DR, McDonald-Smith GP, Gao H, Hennessy L, et al: Genomic responses in mouse models poorly mimic human inflammatory diseases. Proc Natl Acad Sci USA 110: 3507-3512, 2013.

30. Mitka M: Drug for severe sepsis is withdrawn from market, fails to reduce mortality. JAMA 306: 2439-2440, 2011.

31. Mestas $\mathbf{J}$ and Hughes CC: Of mice and not men: Differences between mouse and human immunology. J Immunol 172 2731-2738, 2004

32. Warren HS, Fitting C, Hoff E, Adib-Conquy M, Beasley-Topliffe L, Tesini B, Liang X, Valentine C, Hellman J, Hayden D and Cavaillon JM: Resilience to bacterial infection: Difference between species could be due to proteins in serum. J Infect Dis 201: 223-232, 2010.

33. Xu Y, Chen S, Cao Y, Zhou P, Chen Z and Cheng K: Discovery of novel small molecule TLR4 inhibitors as potent anti-inflammatory agents. Eur J Med Chem 154: 253-266, 2018.

34. Andresen L, Theodorou K, Grünewald S, Czech-Zechmeister B, Könnecke B, Lühder F and Trendelenburg G: Evaluation of the therapeutic potential of Anti-TLR4-antibody MTS510 in experimental stroke and significance of different routes of application. PLoS One 11: e148428, 2016.

35. Neal MD, Jia H, Eyer B, Good M, Guerriero CJ, Sodhi CP, Afrazi A, Prindle T Jr, Ma C, Branca M, et al: Discovery and validation of a new class of small molecule Toll-like receptor 4 (TLR4) inhibitors. PLoS One 8: e65779, 2013.

36. Ohta S, Bahrun U, Shimazu R, Matsushita H, Fukudome K and Kimoto M: Induction of long-term lipopolysaccharide tolerance by an agonistic monoclonal antibody to the toll-like receptor 4/MD-2 complex. Clin Vaccine Immunol 13: 1131-1136, 2006.

37. Akashi-Takamura S, Furuta T, Takahashi K, Tanimura N, Tanimura N, Kusumoto Y, Kobayashi T, Saitoh S, Adachi Y, Doi $\mathrm{T}$ and Miyake K: Agonistic antibody to TLR4/MD-2 protects mice from acute lethal hepatitis induced by TNF-alpha. J Immunol 176: 4244-4251, 2006.

38. Wang M, Zheng W, Zhu X, Xu J, Cai B, Zhang Y, Zheng F, Zhou L, Yang Z, Zhang X, et al: A human anti-Toll like receptor $4 \mathrm{Fab}$ fragment inhibits lipopolysaccharide-induced pro-inflammatory cytokines production in macrophages. PLoS One 11: e146856, 2016.

39. Park BS, Song DH, Kim HM, Choi BS, Lee H and Lee JO: The structural basis of lipopolysaccharide recognition by the TLR4-MD-2 complex. Nature 458: 1191-1195, 2009.

40. Eckert JK, Kim YJ, Kim JI, Gürtler K, Oh DY, Sur S, Lundvall L, Hamann L, van der Ploeg A, Pickkers P, et al: The crystal structure of lipopolysaccharide binding protein reveals the location of a frequent mutation that impairs innate immunity. Immunity 39: 647-660, 2013.

41. Kim JI, Lee CJ, Jin MS, Lee CH, Paik SG, Lee H and Lee JO: Crystal structure of CD14 and its implications for lipopolysaccharide signaling. J Biol Chem 280: 11347-11351, 2005.

42. Kim SJ and Kim HM: Dynamic lipopolysaccharide transfer cascade to TLR4/MD2 complex via LBP and CD14. BMB Rep 50: $55-57,2017$

This work is licensed under a Creative Commons Attribution-NonCommercial-NoDerivatives 4.0 International (CC BY-NC-ND 4.0) License. 